\title{
AVALIAÇÃO DA QUALIDADE E DIVERSIDADE DA PAISAGEM DO PARQUE SÃO LOURENÇO PARA FINS RECREATIVOS E TURÍSTICOS
}

\author{
Raquel Ribeiro de Souza Silva ${ }^{1}{ }^{2}$, Daniela Biondi ${ }^{3}$, Michella Yamamura ${ }^{4}$, Daros Augusto Teodoro da Silva ${ }^{5}$
}

\section{RESUMO}

Esta pesquisa analisou a qualidade visual da paisagem no Parque São Lourenço - Curitiba - PR, por meio do método indireto e direto. No método indireto, foi utilizada uma imagem digital de satélite da área total do parque para a classificação dos elementos da paisagem e análise de fotografias. No mapa das classes de qualidade da paisagem sem o fator diversidade $52,1 \%$ das quadrículas receberam classificação boa; $8,4 \%$ média; e 4,2\% ruim. No mapa das classes de qualidade da paisagem com o fator diversidade, 8,4\% das quadrículas receberam classificação boa; $31 \%$ média; e 25,2\% ruim. No método direto, foram aplicados 84 questionários, onde os entrevistados atribuíram valor a qualidade visual apresentada nas fotografias tiradas nas quadrículas representadas nos mapas de classe de qualidade da paisagem. Os resultados considerando o fator diversidade foram $11 \%$ para a quadrícula considerada BOA; $11,61 \%$ para a MÉDIA; e 8,26\% para a RUIM. Sem considerar o fator diversidade $10,69 \%$ para a quadrícula considerada BOA; 6,21\% para a MÉDIA; e 6,48\% para a RUIM. O fator diversidade no método indireto super valorizou algumas quadrículas, não coincidindo com os valores encontrados no método direto. Estes resultados podem contribuir para o planejamento da paisagem e subsidiar planejamentos turísticos e recreativos.

Palavras-chave: Áreas verdes; Turismo; Recreação; Preferência paisagística.

\section{LANDSCAPE EVALUATION AT SÃO LOURENÇO PARK FOR TOURISM AND RECREATIONAL PURPOSES}

\begin{abstract}
This research examined the landascape visual quality of São Lourenço Park at Curitiba - PR, through direct and indirect methods. At the indirect method, a digital satellite image of the total park area was used for the classification of landscape elements and analysis of pictures. On the landscape class quality map without the diversity factor $52,1 \%$ of the grids were rated as good; $8,4 \%$ as average and $4,2 \%$ as poor. On the landscape class quality map with the diversity factor, $8,4 \%$ of the grids were rated as good; $31 \%$ as average and $25,2 \%$ as poor. At the direct method were applied 84 questionnaires where respondents attributed value to the pictures visual quality which were taken in the grids represented on the landscape class quality map. The results considering the diversity factor were $11 \%$ for the GOOD grid; $11,61 \%$ for the AVERAGE grid and $8,26 \%$ for the POOR grid. The results without considering the diversity factor were $10,69 \%$ for the GOOD grid; $6,21 \%$ for the AVERAGE grid and 6, 48\% for the POOR grid. The diversity factor at the indirect method super appreciated some grids, do not matching values found at the direct method. These results may contribute to the landscape planning and subsidizing tourism and recreational planning.
\end{abstract}

Keywords: Green areas; Tourism; Recreation; Landscape preference.

\footnotetext{
${ }^{1}$ Bal. em Turismo, Mestranda em Engenharia Florestal, UFPR, Curitiba, PR, unesp2004@yahoo.com.br.

${ }^{2}$ Data recebimento: 30/11/2011 - Data de publicação: 15/12/2012

${ }^{3}$ Engenheira Florestal, Prof. ${ }^{a}$ Dra. em Engenharia Florestal, UFPR, Curitiba, PR, dbiondi@ufpr.br.

${ }^{4}$ Engenheiro Florestal, Me. Doutoranda em Engenharia Florestal, UFPR, Curitiba, PR, myamamura@uol.com.br.

${ }^{5}$ Engenheiro Florestal, Me. Doutorando em Engenharia Florestal, UFPR, Curitiba, PR, darosaugusto@yahoo.com.br.
} 


\section{INTRODUÇÃO}

Os parques, áreas verdes de uso público, são locais criados com múltiplos objetivos, como para a conservação da biodiversidade, para a realização de atividades de lazer, recreação e até mesmo turismo.

A cidade de Curitiba é um exemplo de localidade que se preocupa com a manutenção de suas áreas verdes, sejam elas parques, jardins, bosques, entre outras tipologias, agregando a elas valor estético e turístico.

Tratando-se da paisagem existente nestes espaços, esta pode ser formada por elementos naturais, artificiais e culturais Forman e Godron (1986) Bombín (1987), Bolós (1992) e Nucci (2007), sendo que neste contexto, o homem além de observador, é considerado também um dos elementos que compõem o panorama paisagístico (BIONDI, 1990; SHAMA, 1995).

Nota-se, que a combinação dos elementos naturais, culturais e antrópicos proporcionam à paisagem um alto grau de atratividade (Bolós, 1992) e funciona também como instrumento para dimensionar a capacidade de uso de determinada área para finalidades de lazer e turismo.

Desta forma, a qualidade visual da paisagem, vai depender da qualidade dos elementos que a compõem, os quais influenciarão diretamente a qualidade visual do entorno imediato e a qualidade das belezas cênicas locais.

Além do fator estético a qualidade visual da paisagem está também condicionada a um alto grau de subjetividade, sendo percebida e avaliada das mais diversas formas de acordo com as preferências do observador e uma expressão de valores emocionais (BOLÓS, 1992; CONESA, 1997).
Assim, no momento de estabelecer valores que determinaram a qualidade da paisagem, é necessária utilização de metodologias de avaliação paisagística, as quais podem ser direta indireta ou mista, onde os valores são estipulados de acordo com a preservação dos componentes paisagísticos presentes na área de estudo.

Pires (1993) utilizou o método indireto para avaliar a qualidade visual da paisagem e ressaltou que o juízo de valor permite estabelecer as variáveis e os critérios de avaliação a serem aplicados na paisagem em análise e a importância em se conhecer as características territoriais, bem como a disponibilidade e qualidade dos dados a serem utilizados em estudos paisagísticos.

Bastarz (2009) utilizou métodos diretos e indiretos para avaliar a preferência da paisagem no município de Morretes com o objetivo de subsidiar o planejamento turístico local, onde a valoração paisagística foi realizada por intermédio da aplicação do método Q.

Em um estudo sobre a gestão da paisagem e desenvolvimento turístico na cidade de caso Curitiba Hartd e Hardt (2010) utilizaram-se da integração dos métodos direto, indireto, misto e integrado para avaliação da paisagem e diagnosticaram que no entorno dos atrativos turísticos as interferências visuais da expansão urbana tendem a deteriorar a qualidade da paisagem.

Considerando que o Parque São Lourenço é uma área verde integrante dos atrativos turísticos da cidade de Curitiba, o qual possui também forte potencial recreativo, o objetivo deste trabalho é analisar a qualidade e a diversidade paisagística 


\section{MATERIAL E MÉTODOS}

\section{Caracterização da área de estudo}

O Parque São Lourenço localiza-se na zona norte do município de Curitiba e possui uma área de
$203.918 \mathrm{~m}^{2}(20,4 \mathrm{ha})$, conforme demonstra a figura 1:

Figura 1. Localização do Parque São Lourenço

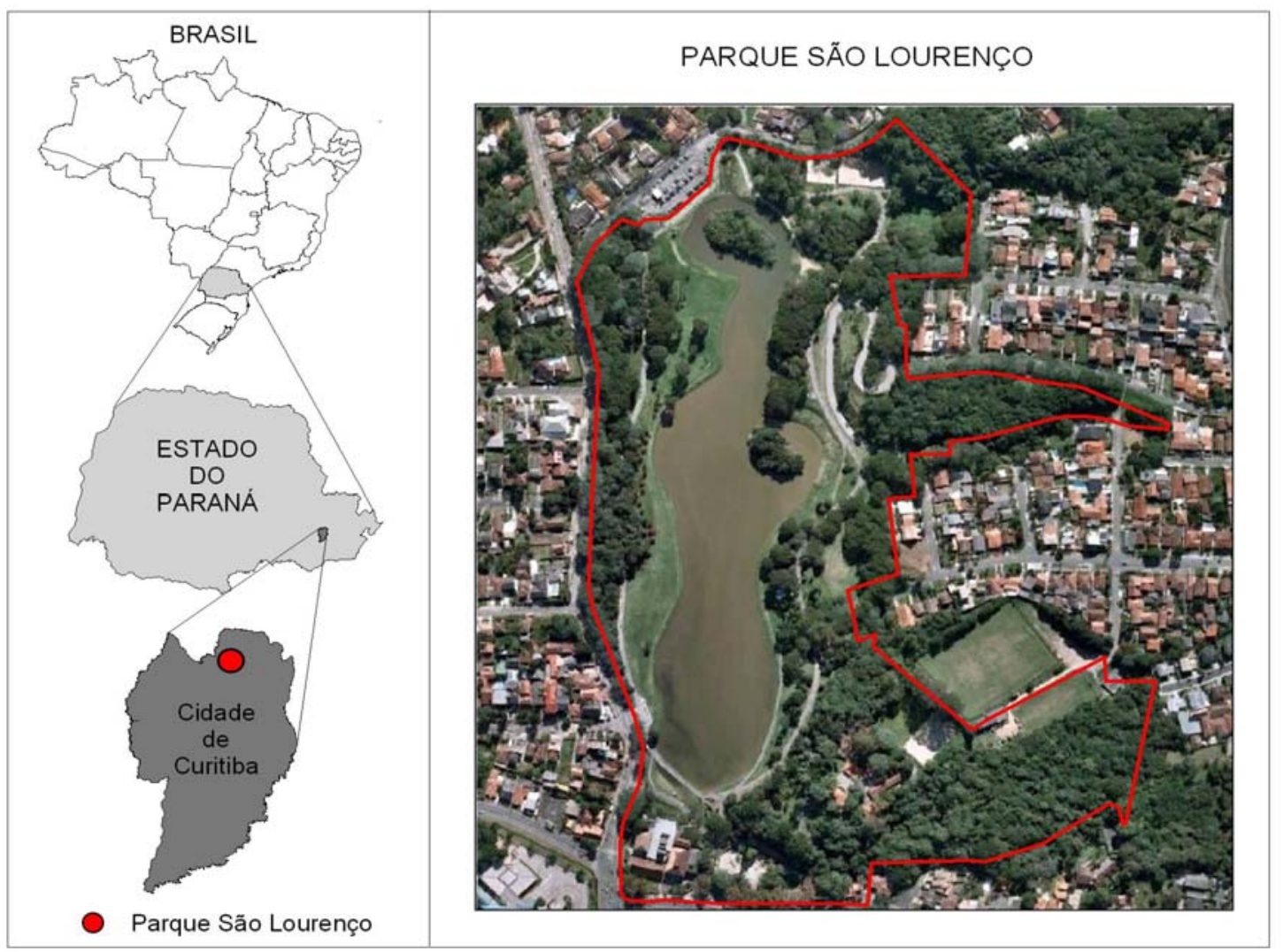

Segundo dados do IPPUC (2011), a criação do Parque São Lourenço se deu em 1972, após a grande inundação de 1970, que ocasionou o estouro da represa São Lourenço. Uma parcela significativa de sua área é ocupada por um reservatório das águas do Rio Belém, com finalidade de regulação de enchentes. Conforme observado em estudo de campo, este lago é a atração dominante do local.

O funcionamento do Parque São Lourenço teve inicio no espaço de uma antiga fábrica de cola, cuja chaminé de tijolos à vista pode ser visualizada de longe, e transformar seu maquinário em esculturas, que formam o Centro de Criatividade. Cinco pavilhões da antiga fábrica foram reciclados $\mathrm{e}$ adaptados para abrigar o atelier de artes e ofícios, o auditório, o espaço de exposições e a biblioteca, espaços que compõem o apoio à criatividade (IPPUC, 2011).

Desde junho de 1998, como ação de incentivo cultural, depois de remontada e restaurada, ao lado 
do atelier de escultura, funciona a casa do escultor Erbo Stenzel. O local abriga exposições e acolhe o acervo e a documentação deste escultor, gravador, impressor, desenhista e professor paranaense (IPPUC, 2011).

Os equipamentos e serviços disponíveis aos usuários do Parque São Lourenço são: play-ground, pista de rolimã, pista de cooper, churrasqueiras, centro de criatividade, teatro, ateliê, sede administrativa, sanitários, canchas de futebol e vôlei, ponte, ciclovia, lago, estacionamento e posto policial.

Os aspectos naturais do Parque São Lourenço são representados pela fauna, composta por preá, roedores silvestres, gambá, morcego, sabiá, socó, biguá, saracura quero-quero, coleirinha, pintassilgos tico-tico, galinha-de-angola, pica-pau, coruja e gavião; e pela flora, que é composta por capão de floresta nativa e espécies como aroeira, araçá, alfeneiro, extremosa, pinheiro-bravo, canela, pau-de-bugre, pitangueira, etc (IPPUC, 2011).

O Parque São Lourenço está sempre aberto e o acesso de ônibus se dá pelas linhas Abranches, Vila Suíça, Jardim Chaparral e Taboão-Água-Verde, Interbairros II (Terminal Cabral) e por meio da linha turismo.

Apesar da existência de infraestrutura recreativa e turística, e facilidade de acesso, no ranking dos parques mais visitados de Curitiba, elaborado pelo IPPUC, o Parque São Lourenço, figura com uma visitação inexpressiva, conforme demonstra a Tabela 1.

Tabela 1. Ranking parques mais visitados em 2007

\begin{tabular}{lcc}
\hline PARQUES & CITAÇÕES & POSIÇÃO \\
\hline Parque Barigui & $9,23 \%$ & $1^{\circ}$ \\
Parque Tanguá & $8,41 \%$ & $2^{\circ}$ \\
Parque Tingui & $1,52 \%$ & $3^{\circ}$ \\
Parque São Lourenço & $1,17 \%$ & $4^{\circ}$ \\
Parque Passaúna & $0,12 \%$ & $5^{\circ}$ \\
Outros Parques & $0,23 \%$ & $6^{\circ}$ \\
\hline
\end{tabular}

No levantamento de campo comprovou-se que no uso público do Parque São Lourenço predomina a presença de moradores do entorno e não de visitantes, pois as atividades visualizadas em seu perímetro foram a prática de cooper, de caminhada e a utilização do playground, divergindo das atividades realizadas por visitantes, as quais são, normalmente, centradas na contemplação passiva da paisagem e elaboração de fotografias.

\section{Procedimento metodológico para avaliação da paisagem}

A avaliação da qualidade e diversidade da paisagem do Parque São Lourenço foi feita através de dois métodos: direto e indireto.

\section{Método Indireto}

Este método consiste na análise e valoração da paisagem a partir da contemplação de sua totalidade Aguilo (1984), Gonzalez Bernaldez (1981), Alonso et al. (1983), Escribano (1989) e Alvarez-Alfonso (1990).

Assim, a partir de imagem digital de satélite obtida por meio do programa Google Earth $^{\circledR}$ e georreferenciada junto à Superintendência de Desenvolvimento de Recursos Hídricos e Raquel Ribeiro de Souza Silva et al. 
Saneamento Ambiental (SUDERHSA, 2002), a área total do parque foi dividida a partir da classificação dos elementos da paisagem nas seguintes classes: Gramado, Vegetação Arbóreoarbustiva, Água, Pavimentação, Pista (de caminhada), Lazer e Edificações.

Tabela 2. Classificação dos elementos da paisagem do Parque São Lourenço
A cada uma dessas classes foi atribuído um peso, de acordo com as opiniões discutidas e consensuadas entre os integrantes do grupo, como demonstrado na tabela 2 .

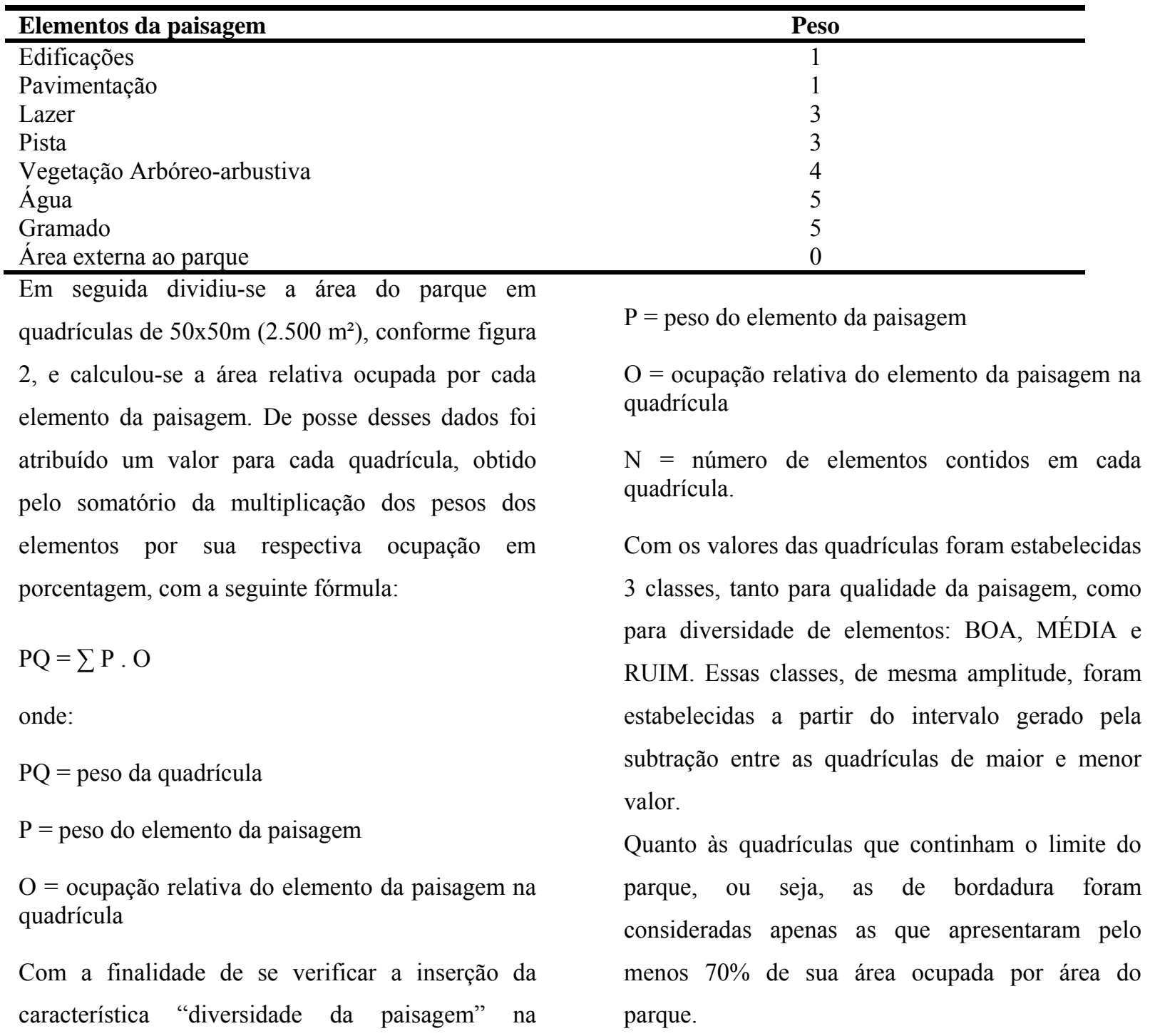

avaliação de cada quadrícula, multiplicou-se o peso da quadrícula (PQ) pelo número de elementos nela contidos (de 1 a 8 ) como segue:

$\mathrm{PQ}_{\mathrm{d}}=\sum \mathrm{P} . \mathrm{O} . \mathrm{N}$

onde:

$\mathrm{PQ}_{\mathrm{d}}=$ peso da quadrícula com diversidade

\section{Método Direto}

Este método, segundo Aguilo (1984), Gonzalez Bernaldez (1981), Alonso et al. (1983), Escribano (1989) e Alvarez-Alfonso (1990), consiste em valorar a paisagem através da análise de seus componentes seguido de avaliação estatística. 
Figura 2. Mapa do Parque São Lourenço em quadrículas

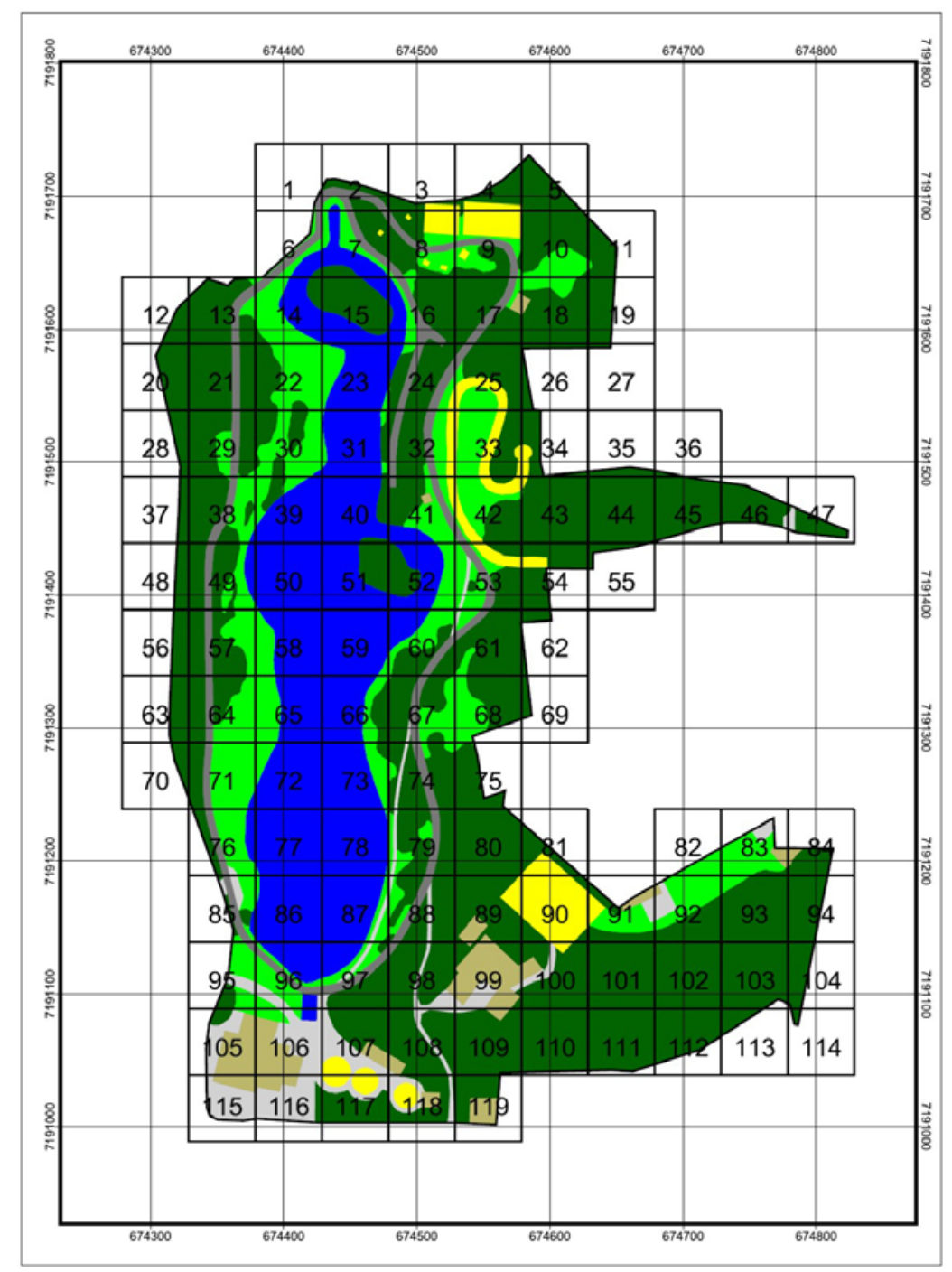

A partir das avaliações realizadas com o método indireto, descrito anteriormente, foram selecionadas as quadrículas que representavam o centro das classes BOA, MÉDIA e RUIM, das duas avaliações, para posterior análise por meio do método direto.

Para a avaliação direta, foram tiradas 4 (quatro) fotografias por meio de câmera digital (SONY Cibershot 7.1) a partir do centro de cada quadrícula, nos sentidos Norte, Leste, Sul e Oeste, com o auxílio de uma bússola (base no norte magnético dos dias 9/06 e 16/06 de 2010).
As fotografias foram então dispostas em seqüência, em um documento (duas por página), com as alternativas de avaliação logo abaixo de cada fotografia: "BOM ( )”, "MÉDIO ( )”, "RUIM ( )". Essas classes ou categorias se referiam ao quanto cada fotografia agradava ao observador. Foram estabelecidos valores numéricos para cada uma dessas classes, sendo 3, 2 e 1, respectivamente. Cada ponto amostrado recebeu quatro avaliações, uma por fotografia, e cada fotografia recebeu um valor, por observador. Sendo assim, para cada observador, os pontos amostrados tiveram uma 
pontuação, gerada pelo somatório das avaliações individuais de cada fotografia, conforme a tabela 3.

Em seguida, foi verificada a freqüência das classes

avaliadas pelos observadores, obtendo-se uma classificação final das quadrículas para comparação com a avaliação indireta.

Tabela 3. Classificação e Limites de Classe das quadrículas selecionadas para avaliação direta da qualidade visual paisagem do Parque São Lourenço, por meio de fotografias

\begin{tabular}{ccc|c}
\hline Classificação & \multicolumn{2}{c}{ Limites de Classe } \\
\hline RUIM & 4,00 & $\mid----$ & 6,67 \\
MÉDIO & 6,67 & $----9,33$ \\
BOM & 9,33 & $----12,00$ \\
\hline
\end{tabular}

\section{RESULTADOS E DISCUSSÃO}

\section{Método Indireto}

De acordo com os cálculos efetuados para a escolha das quadrículas, foram gerados dois mapas: um considerando o fator diversidade e o outro sem considerar este fator, ambos representados por meio das quadrículas coloridas na figura 3.

Figura 3. Quadrículas avaliadas (A) Com diversidade. (B) Sem diversidade. Vermelho: Ruim. Laranja: Média. Amarelo: Boa.

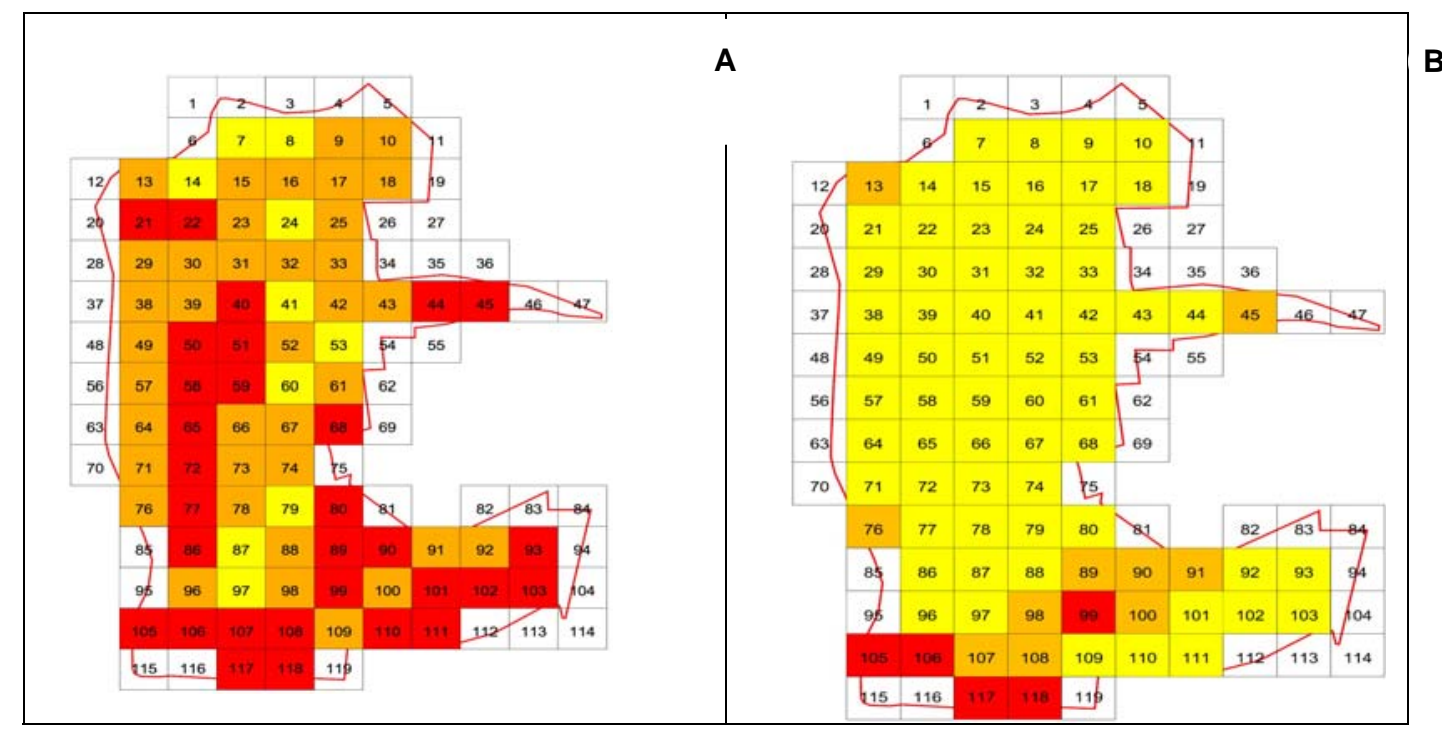

Para a classificação do mapa de acordo com as classes de qualidade da paisagem com o fator diversidade, obtiveram-se os seguintes resultados:

- 8,4\% das quadrículas com classificação boa;

- 31\% das quadrículas com classificação média;

- 25,2\% das quadrículas com classificação ruim.
A partir desses resultados, elaborou-se um gráfico de freqüência de classes, para o fator diversidade (Figura 4). 
Figura 4. Gráfico ilustrando as freqüências das quadrículas com diversidade nas três classes: ruim, média e boa

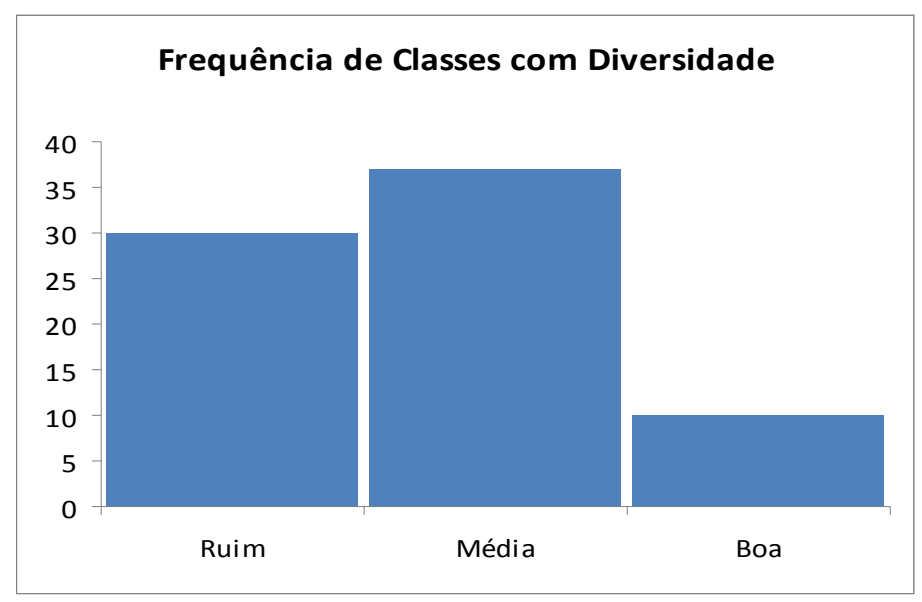

Para a classificação do mapa de acordo com as

A partir desses resultados, elaborou-se um gráfico classes de qualidade da paisagem sem o fator de freqüência de classes, sem o fator diversidade diversidade, obtiveram-se os seguintes resultados: (Figura 5).

- 52,1\% das quadrículas com classificação boa;

- 8,4\% das quadrículas com classificação média;

- 4,2\% das quadrículas com classificação ruim.

Figura 5 - Gráfico ilustrando as freqüências das quadrículas sem diversidade nas três classes: ruim, média e boa

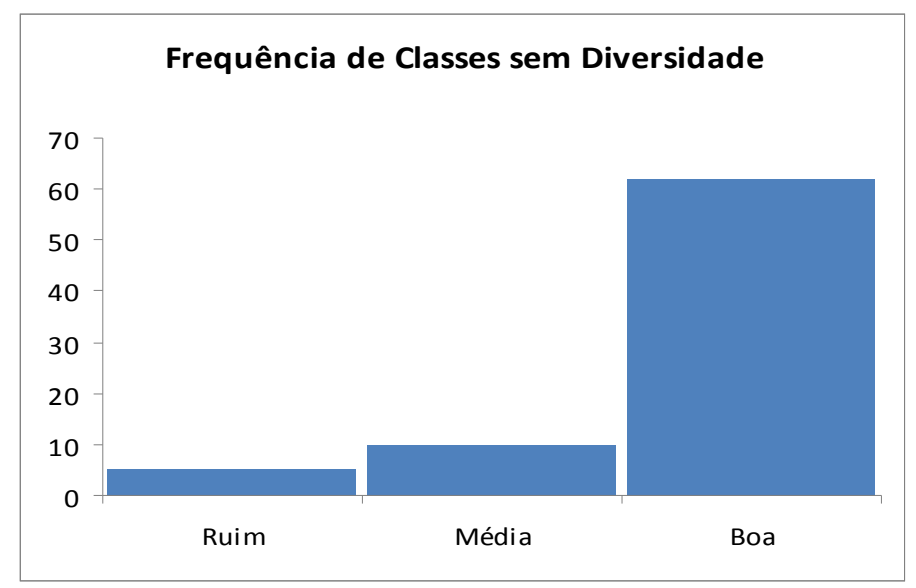

\section{Com fator diversidade}

Ao visitar o parque nas quadrículas selecionadas, pôde-se observar que os resultados obtidos não condiziam com as condições do local. O que foi valorizado, em teoria, como diversidade no mapa, o local não apresentava qualidade visual significativa. Como exemplo, a quadrícula 7 (Figura 6). 
Figura 6. Paisagens tomadas a partir da quadrícula 7 do Parque São Lourenço. (A) Sentido Norte. (B) Sentido Leste. (C) Sentido Sul. (D) Sentido Oeste

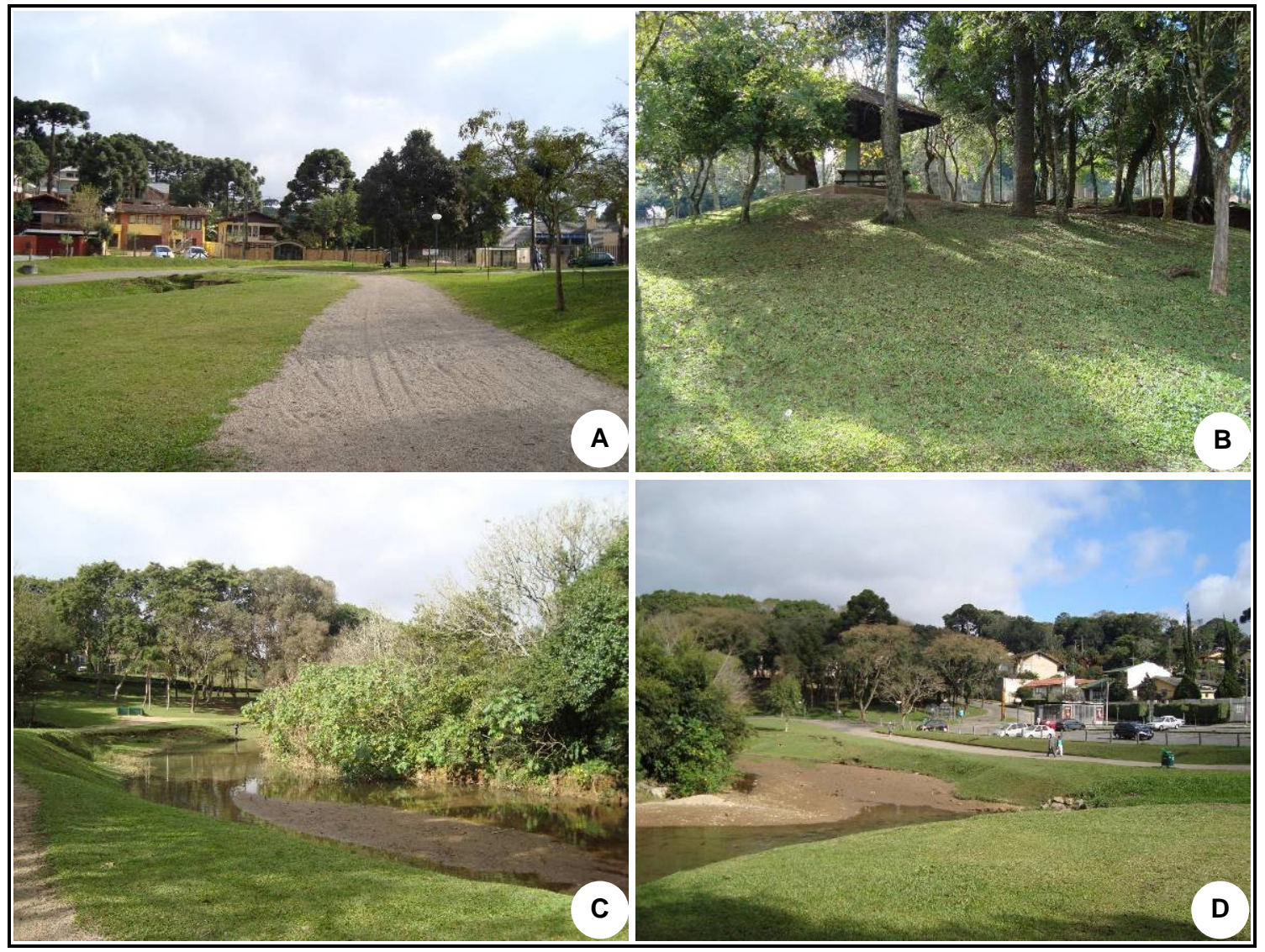

A quadrícula que obteve o valor médio foi a 66. In loco pôde-se observar que a sua qualidade visual era melhor do que a quadrícula 7 , que foi considerada a melhor no quesito diversidade (Figura 7).

Figura 7. Paisagens tomadas a partir da quadrícula 66 do Parque São Lourenço. (A) Sentido Norte. (B) Sentido Leste. (C) Sentido Sul. (D) Sentido Oeste

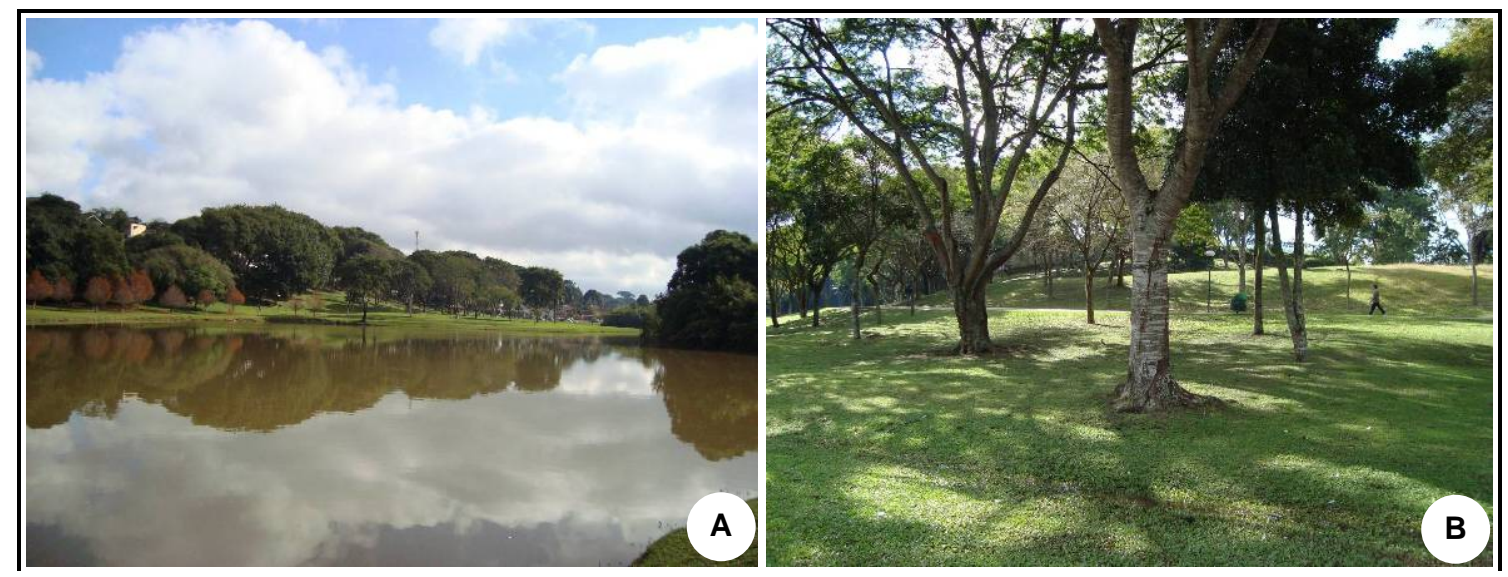




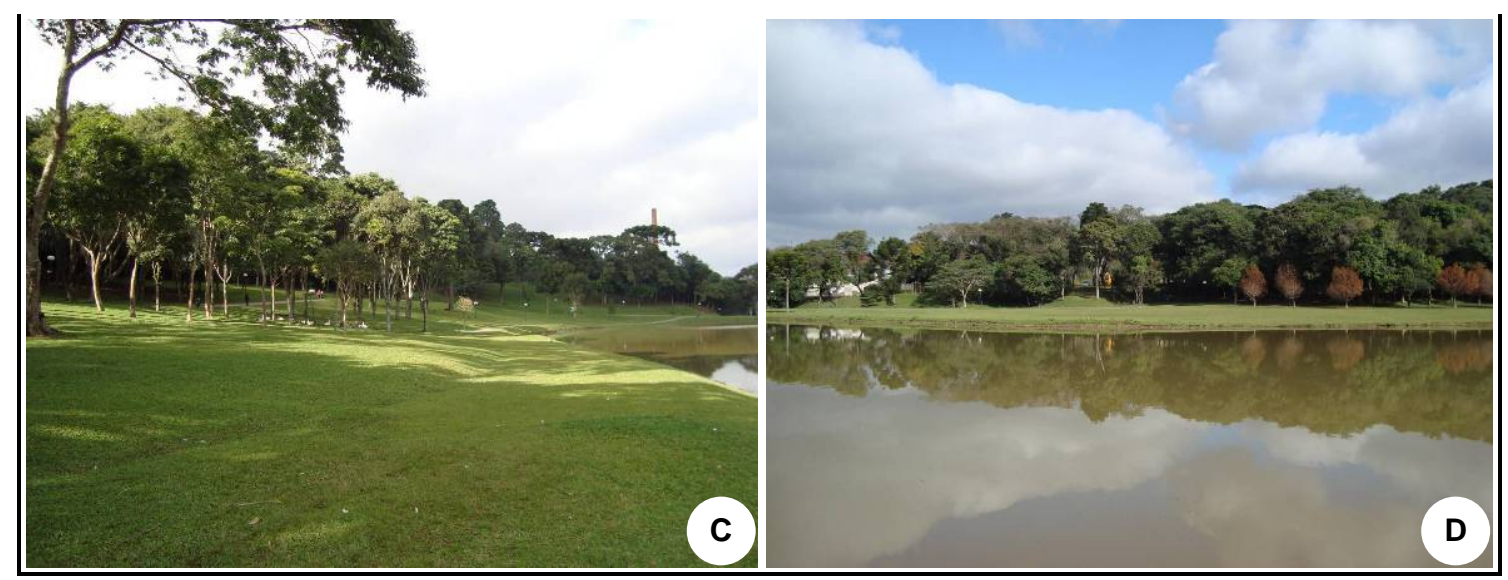

Já a quadrícula que obteve o menor valor, com diversidade, foi a de número 117. Esta quadrícula na qualidade da paisagem para os usuários do não possui uso público, sendo assim, não interfere parque (Figura 8).

Figura 8. Paisagens tomadas a partir da quadrícula 117 do Parque São Lourenço. (A) Sentido Norte. (B) Sentido Leste. (C) Sentido Sul. (D) Sentido Oeste

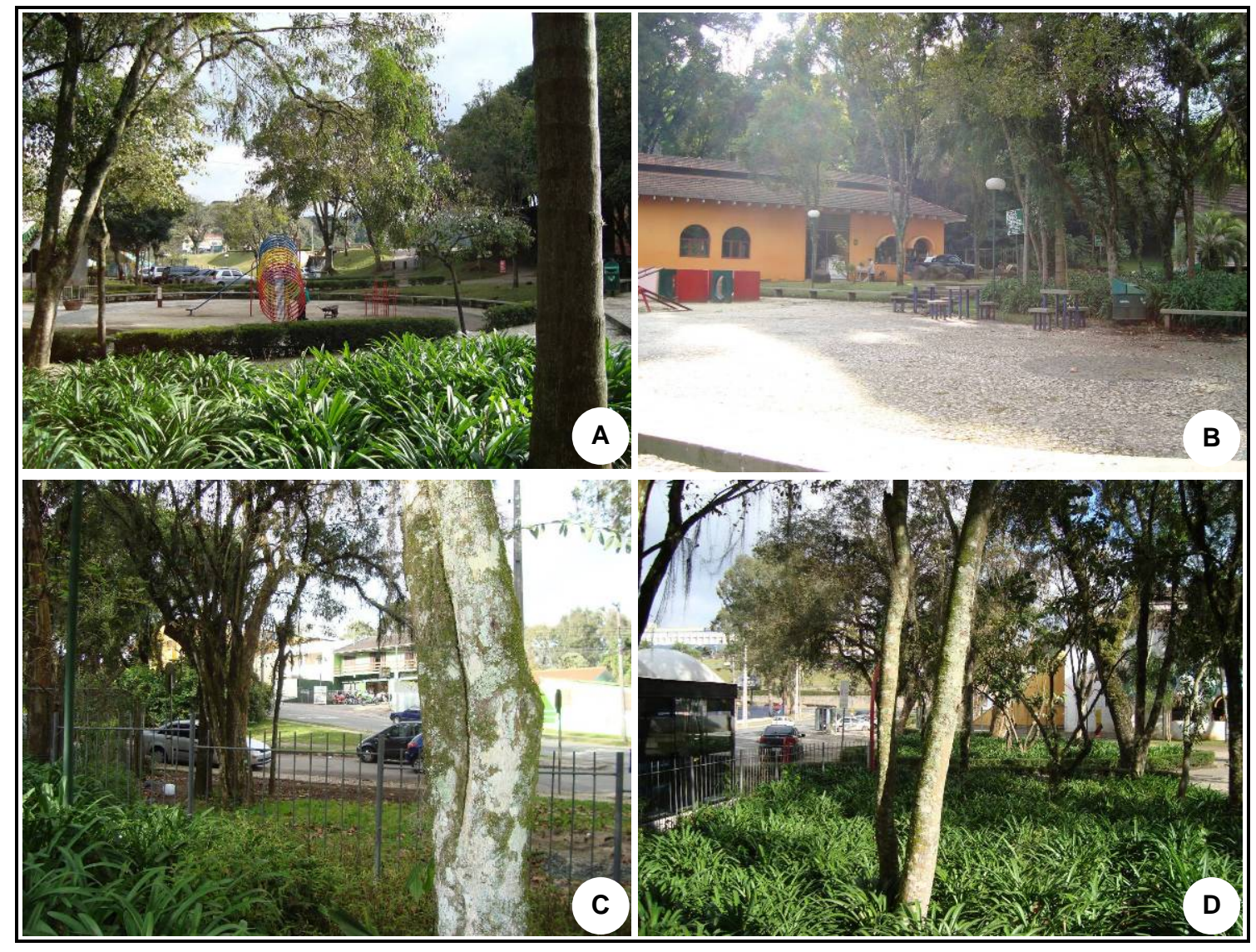

Raquel Ribeiro de Souza Silva et al. 
Nota-se que a maioria das quadrículas $(n=37)$ recebeu classificação mediana, ou seja, "MÉDIA", distribuída por toda a área do parque. As quadrículas classificadas como "RUIM", também ficaram bem distribuídas, porém em número pouco menor $(n=30)$. Já as quadrículas de classificação "BOA" foram poucas $(\mathrm{n}=10)$, mas com boa distribuição ao longo do parque.

Observou-se que o fator diversidade teve uma influência significativa no resultado da avaliação, no entanto, ao se comparar estes resultados com a avaliação direta, onde a opinião pessoal é um fator relevante para os objetivos propostos, houve algumas divergências na classificação das quadrículas.

\section{Sem fator diversidade}

Neste método de avaliação pode-se observar certa coerência entre as quadrículas escolhidas e a visualização in loco. A quadrícula considerada como melhor foi a 64 (Figura 9).

Figura 9. Paisagens tomadas a partir da quadrícula 64 do Parque São Lourenço. (A) Sentido Norte. (B) Sentido Leste. (C) Sentido Sul. (D) Sentido Oeste

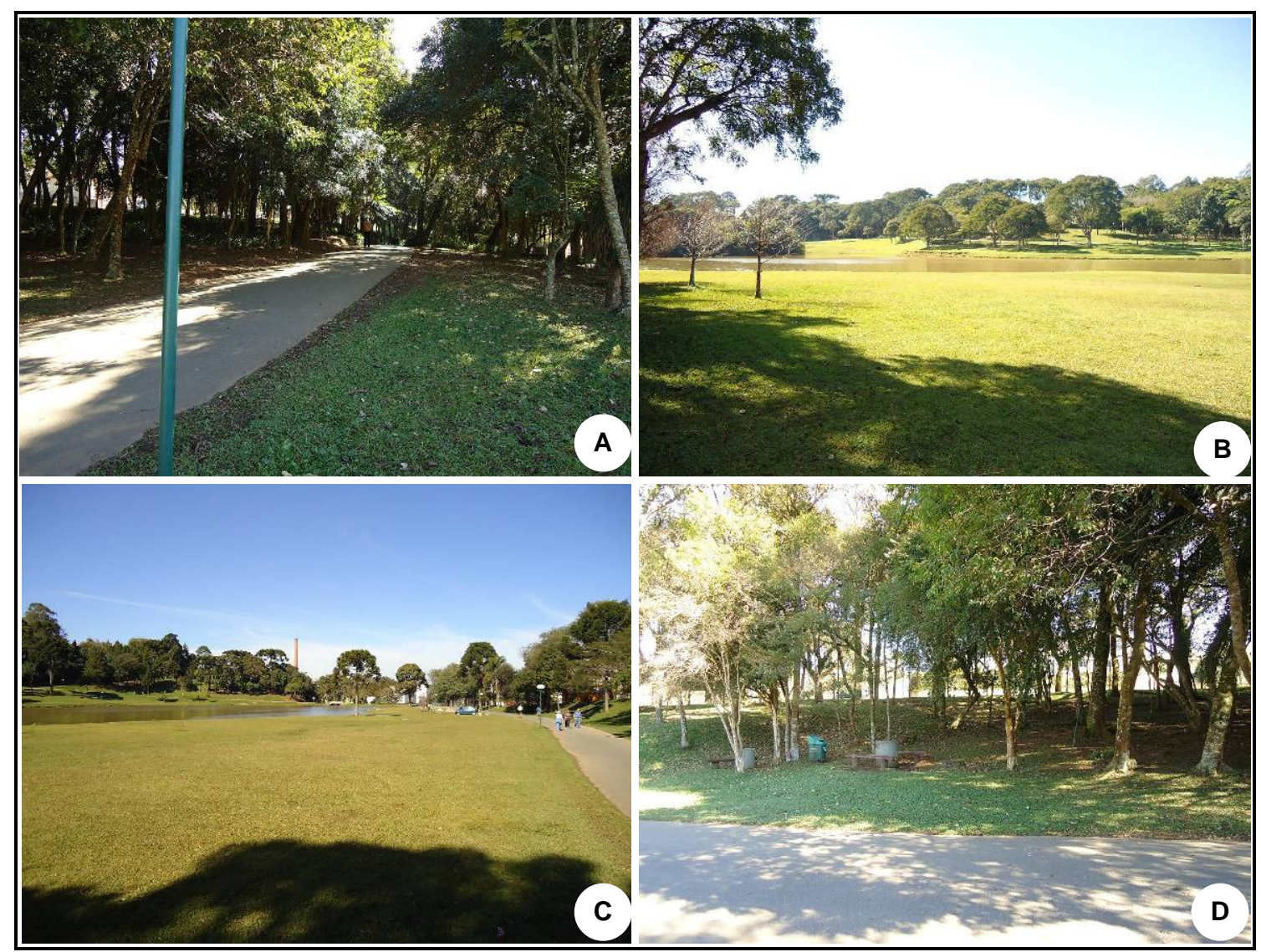

A quadrícula média foi a de número 107, sendo que, in loco, observou-se que ela não tinha atributos necessários para ser visualmente atrativa e ser escolhida como média (Figura 10). 
Figura 10. Paisagens tomadas a partir da quadrícula 107 do Parque São Lourenço. (A) Sentido Norte. (B) Sentido Leste. (C) Sentido Sul. (D) Sentido Oeste

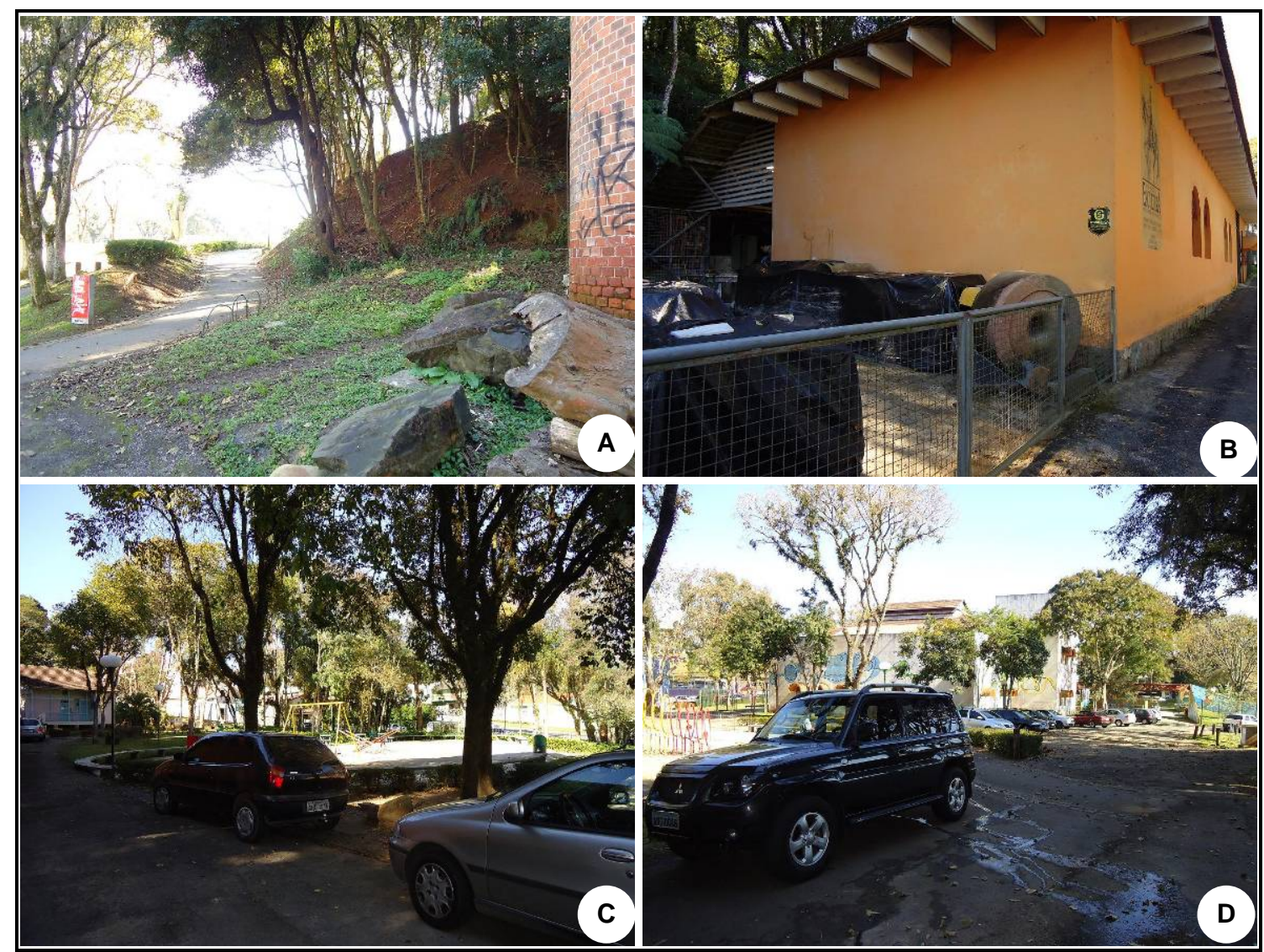

A quadrícula de número 106 foi escolhida como sendo a pior. In loco, realmente pôde-se constatar que não tinha atrativo visual nenhum (Figura 11). As paisagens melhor avaliadas foram as que são mais utilizadas pelos visitantes, assim como apresentaram o melhor valor visual, como a pista de caminhada, os equipamentos de ginástica, o campo de futebol e a pista de rolimã.

O playground (quadrículas 107, 117 e 118), por exemplo, por estar mais próximo das edificações e mais afastado do lago, teve a qualidade visual comprometida e as quadrículas que o continham tiveram classificação "RUIM" ou "MÉDIA", pelos dois métodos de avaliação. Como a finalidade desta área é a recreação, esta também pode ser comprometida, por não oferecer ao visitante um ambiente visualmente agradável.

A quadrícula 7, no extremo norte do parque, foi classificada como "BOA" no método indireto "com diversidade", pois possuía 5 dos 7 elementos considerados para composição do fator “diversidade", além de estes 5 elementos possuírem um peso maio na pontuação. No método direto essa quadrícula também foi classificada como "BOA".

A quadrícula 66, no método indireto "com diversidade", teve classificação "MÉDIA", porém, na avaliação pelo método direto foi unânime a 
opinião dos observadores sobre a sua "BOA" qualidade visual.

Possivelmente o fator que mais contribuiu para este último resultado foi a localização centralizada da quadrícula, que abrange a visão de quase todo o lago, ladeado pelo gramado e com a vegetação arbórea ao fundo. A composição destes elementos tem aspecto agradável ao público.

Figura 11. Paisagens tomadas a partir da quadrícula 106 do Parque São Lourenço. (A) Sentido Norte. (B) Sentido Leste. (C) Sentido Sul. (D) Sentido Oeste


Na avaliação das quadrículas 106 e 107, em ambos os métodos, estas foram classificadas como "RUIM" e "MÉDIA", mas com a inversão de valores somente na quadrícula 107. Essa divergência pode ter sido causada pela paisagem do entorno das quadrículas, que ora continham edificações e pavimentos, ora áreas com bosques em meio à pavimentação e áreas de recreação.

Bobrowski et al. (2010) em seu trabalho de avaliação da qualidade visual do Parque Tangá, constatou que elementos urbanos, tais como edificações e construções arquitetônicas possuem uma valoração negativa, enquanto que os elementos naturais, tais como vegetação, água, relevo, céu possuem uma valoração positiva.

A avaliação "BOA" atribuída à quadrícula 64 foi confluente nos dois métodos, devido à sua localização, como na quadrícula 66 , e também pela pontuação dos elementos nela contidos. 
Isso demonstra que o método indireto pode ser útil para determinados fins, mas nem tanto para outros, como neste caso, onde se pretende verificar a qualidade visual do parque.

\section{Método Direto}

Tabela 4. Valores médios de cada quadrícula
Para este método foram aplicados 84 questionários, sendo 42 com diversidade e 42 sem diversidade, onde os entrevistados tiveram que analisar a qualidade visual apresentada por cada fotografia. Os valores médios obtidos para as quadrículas avaliadas pelos voluntários estão na Tabela 4:

\begin{tabular}{lcccccc}
\hline \multirow{2}{*}{ Classe } & \multicolumn{3}{c}{ Com Diversidade } & \multicolumn{3}{c}{ Sem Diversidade } \\
\cline { 2 - 7 } & Boa & Média & Ruim & Boa & Média & Ruim \\
\hline Quadrícula & 7 & 66 & 117 & 64 & 107 & 106 \\
Valor Médio & 10,11 & 11,61 & 8,26 & 10,69 & 6,21 & 6,48 \\
\hline
\end{tabular}

Por meio do método direto o resultado da classificação das quadrículas foi diferente do esperado pelo método indireto para algumas quadrículas. Na situação em que se considerou o fator diversidade, o método indireto subestimou $\mathrm{o}$ valor das quadrículas, e quando este fator foi excluído da análise, as quadrículas de classificação "BOA" e "RUIM" tiveram concordância, mas a quadrícula "MÉDIA" teve seu valor alterado.

Diferente do encontrado por Bastarz (2009), onde o fator diversidade apresentou influência positiva na valoração da paisagem de Morretes, no presente trabalho houve uma influência negativa na valoração da paisagem ao se considerar este mesmo fator.

Gonzaga et al. (2004), os quais se valeram da análise de dados coletados diretamente em campo e por meio de fotografias, para a avaliação da paisagística do Parque Municipal do Passaúna, também verificaram variação nos resultados obtidos, com a ressalva de que as divergências detectadas poderiam ser atribuídas à "menor quantidade de informações contidas em uma imagem, restringindo a possibilidade do avaliador perceber a paisagem em sua totalidade".

A discordância de resultados encontradas por meio dos dois métodos utilizados neste trabalho reforça também a afirmação de Oliveira (2003), sobre a insuficiência de uma avaliação com base apenas no método indireto para obter uma visão precisa do que se pretende avaliar, sendo necessário recorrer a avaliações diretas in loco.

\section{CONCLUSÃO}

Os resultados obtidos neste trabalho por meio do método indireto proporcionaram uma visão mais generalizada de toda a área, sem, no entanto, demonstrar as situações que podem ser percebidas pelos usuários do parque. 
Ao se optar pela avaliação indireta da paisagem é preferível excluir o fator "diversidade", quando se utilizar o método aqui descrito, pois este fator supervalorizou algumas quadrículas, quando comparado ao método direto e ao indireto sem o fator diversidade.

Quanto à paisagem específica do Parque São Lourenço, recomenda-se a recuperação das áreas com assoreamento e com degradação da vegetação, na parte norte do parque, pois este foi um dos fatores que contribuíram para a menor valoração daquela região do parque, apesar desse local apresentar potencial paisagístico e turístico, como verificado pelo método indireto.

Por fim, em estudos de avaliação da qualidade da paisagem é aconselhável a utilização de mais de um método de avaliação, pois proporcionam resultados mais condizentes com a realidade do local de estudo e os resultados obtidos por meio destas metodologias constituem-se importantes ferramentas para o planejamento turístico ao detectar as potencialidades e fragilidades de atrativos.

\section{REFERÊNCIAS}

AGUILO, M. Guia para la elaboración de estudios del medio físico: contenido y metodología. Madrid: CEOTMA. 1984.

ALONSO, M.; AGUILO, M.; RAMOS, A. Directrices Técnicas para la estimación de impactos. Madri: E.T.S.I.M, 1983.

ALVAREZ-ALFONSO, R. M. Estúdio y valoracion del paisaje: territorio de Valderejo. 137p. Monografia (Magister em urbanismo y ordenacion del território) - Universidad de Cantábria, Santander, 1990.

BASTARZ, C. Análise da preferência da paisagem do município de Morretes, Paraná como subsídio ao planejamento do turismo. 122p. Dissertação (Mestrado em Engenharia Florestal) - Setor de Ciências Agrárias, Universidade Federal do Paraná, Curitiba, 2009.

BIONDI, D. Paisagismo. Recife: Imprensa Universitária da UFRPE, 1990.

BIONDI, D. e LEAL, C.T. Análise da capacidade paisagística do Parque Estadual de Vila Velha - PR. In: Congresso Brasileiro de Unidades de Conservação, III, Fortaleza. Anais... Fortaleza: Rede Nacional PróUnidades de Conservação/Fundação O Boticário de Proteção à Natureza/Associação Caatinga, 2002. p. 359-367.

BOBROWSKI, R., et al. Qualidade visual da paisagem do Parque Natural Municipal Tanguá, Curitiba - PR. Revsbau, v.5, n.2, Piracicaba - SP, p.19-39, 2010.

BOLÓS y CAPDEVILA, M. Manual de Ciencia del Paisaje: Teoría, Métodos e

Aplicaciones. Barcelona: Masson S.A., 1992.

BOMBÍN, M. M. E. El Paisage. Madri: Ministério de Obras Públicas y Urbanismo, Centro de Publicaciones, 1987.

CONESA, V. Guía metodógica para la evaluación del impacto ambiental. Ediciones Mundi - prensa. 3.ed. Madri,1997.

ESCRIBANO, M. M.; FRUTOS, M.; IGLESIAS, E.; MATAIX, C.; TORRECILLA,I.. El paisage. Madrid: E.T.S.I. Montes, 1989.

FORMAN, R. T. T.; GODRON, M. Landscape Ecology. New York: John Wiley \& Sons, 1986. 
Gayoso, J. VAldiviA, M.A. Guía de Conservación de Paisaje. Projecto Certificación del Manejo Forestal en las Regiones Octava Décima y Doudécima. Universidad Austral de Chile, 1999.

GONZAGA, C.A.M.; WANDEMBRUCK, A.; SEGER, C.D. e BIONDI, D. Análise paisagística da trilha recreativa do Parque Municipal do Passaúna, Curitiba, Paraná. Cadernos da Biodiversidade, v. 4, n. 2, p. 6673, dez. 2004.

GONZÁLEZ BERNALDEZ, F. Ecologia y Paisaje. Madrid: Blume, 1981.

HARDT, L. P. A., HARDT, C. Gestão da qualidade da paisagem e desenvolvimento turístico das cidades: estudo de caso em Curitiba, Paraná. In: Encontro Nacional da Anppas. V, Florianópolis. Anais...Florianopolis, 2010, p. $1-15$.

INSTITUTO DE PESQUISA E PLANEJAMENTO URBANO DE CURITIBA (IPPUC). Histórico dos Parques e Bosques. Disponível em: <www.ippuc.org.br>. Acesso em 31 de maio de 2011.

NUCCI, João Carlos. Caminhos do Futuro: Ecoturismo. São Paulo: IPSIS, 2007.

OLIVEIRA, D. A. Ecologia e Valoração da Paisagem do Entorno da Cidade de Paranaguá. Curitiba: Universidade Federal do Paraná, 2003. (Dissertação de Mestrado).

PIRES, P. S. Avaliação da Qualidade Visual da Paisagem na Região Carbonífera de Criciúma-SC. 72p. Dissertação (Mestrado em Engenharia Florestal) - Setor de Ciências Agrárias, Universidade Federal do Paraná, Curitiba, 1993.

SECRETARIA DE ESTADO DO TURISMO. Estatística - Demanda Turística de Curitiba, 2007. Disponível em: <www.ippuc.org.br/.../Curitiba_em_dados_Pesquisa.asp>. Acesso em 31 de maio de 2010.

SHAMA, S. Landscape and Memory. Londres: Harper Collins, 1995. 